\title{
Expression of heat shock protein 70 in nasopharyngeal carcinomas: different expression patterns correlate with distinct clinical prognosis
}

Man-Bo Cai ${ }^{1,2 \dagger}$, Xiao-Pai Wang ${ }^{3 \dagger}$, Jia-Xing Zhang ${ }^{3 \dagger}$, Hui-Qiong Han ${ }^{1}$, Chao-Chun Liư ${ }^{4}$, Jin-Xin Bei ${ }^{1}$, Ruo-Jun Peng ${ }^{1}$, Yi Liang ${ }^{1}$, Qi-Sheng Feng ${ }^{1}$, Hai-Yun Wang ${ }^{3}$, Li-Zhen Chen ${ }^{1}$, Sha Fư ${ }^{3}$, Tiebang Kang ${ }^{1}$, Jian-Yong Shao ${ }^{1,3^{*}}$ and Yi-Xin Zeng ${ }^{1 *}$

\begin{abstract}
Background: Heat shock protein 70, a stress protein, has been implicated in tumor progression. However, its role in nasopharyngeal carcinoma (NPC) progression has not yet been clearly investigated.

Methods: Immunohistochemistry $(\mathrm{IHC})$ was employed to examine the expression patterns of Hsp70, human leukocyte antigen -A (HLA-A) in NPC tissue samples.

Results: The expression of Hsp70 exhibited different spatial patterns among nuclear, membrane and cytoplasm in 507 NPC tumor tissues. Kaplan-Meier survival analysis demonstrated that different Hsp70 expression patterns are correlated with different patient outcomes. High membranal and cytoplasmic levels of Hsp70 predicted good survival of patients. In contrast, high nuclear abundance of Hsp70 correlated with poor survival. Moreover, the membranal and cytoplasmic levels of Hsp70 were positively correlated with levels of the MHC I molecule HLA-A.

Conclusions: Different Hsp70 expression patterns had distinct predictive values. The different spatial abundance of Hsp70 may imply its important role in NPC development and provide insight for the development of novel therapeutic strategies involving immunotherapy for NPC.
\end{abstract}

Keywords: Nasopharyngeal carcinoma, Heat shock protein 70, Expression, Prognosis

\section{Background}

Nasopharyngeal carcinoma (NPC) is a leading lethal malignancy with a high prevalence in Southeast Asia, especially in the Guangdong, Guangxi and Hong Kong areas in Southern China [1,2]. The incidence rate of NPC is 25-40 cases per 100,000 person-years in the Cantonese region of Southern China [3]. Most NPC tumor cells are poorly differentiated or undifferentiated and have high tendency to invade adjacent regions and metastasize to neck lymph nodes. Radiotherapy (RT) and concurrent chemoradiotherapy (CCRT) are standard treatments for NPC at early stage and advanced stage, respectively [4-6].

\footnotetext{
*Correspondence: shaojy@sysucc.org.cn; zengyx@sysucc.org.cn

${ }^{\dagger}$ Equal contributors

'State Key Laboratory of Oncology in South China, Cancer Center, Sun Yat-Sen University, 651\# Dongfeng Road East, Guangzhou 510060, China ${ }^{3}$ Department of Molecular Diagnostics, Cancer Center, Sun Yat-Sen University, 651\# Dongfeng Road East, Guangzhou 510060, China Full list of author information is available at the end of the article
}

Therapeutic strategies have been studied aiming to improve the survival rate for advanced NPC. Recently, novel therapies based on molecular targets and neoadjuvant chemotherapy (NAC) followed by RT of NPC were promising for advanced lesions $[7,8]$, though need to be validated in more trials. Conventional TNM staging has a strong prognostic implication for NPC [9]; and patients at early-stage are almost curable under RT, however, the prognosis remains poor in a significant number of patients with late-stage NPC [10] . Local failure and distant metastasis are major issues resulting in poor outcomes in NPC patients at advanced-stage [11]. Therefore, it is of clinical value to identify factors that allow for an early diagnosis and the prediction of prognosis and to discover novel therapeutic strategies.

During tumor development, cancer cells frequently encounter a variety of cytotoxic conditions, such as hypoxia and local hyperthermia $[12,13]$. Heat shock proteins

\section{Biomed Central}


(HSPs), also termed stress proteins, are induced by a variety of stresses, such as hyperthermia, and play pivotal roles in tumor cell survival after exposure to unfavorable insults [14]. Among the HSPs, Hsp70 mediates the protection of tumor cells from stress-induced lethal damage by interfering apoptotic pathways $[15,16]$. Furthermore, high cytosolic levels of Hsp70 are frequently associated with a negative clinical outcome and a higher frequency of metastasis [17]. Studies on NPC have shown that high serum levels of Hsp70 are strongly associated with $\mathrm{T}$ classification, metastasis and mortality, indicating a poor prognosis $[18,19]$.

HSPs also have important roles in the immune system as carriers of tumor antigens [20,21]. Hsp70chaperoned peptides derived from the cytosol of human tumors can activate a classical protective T-cell mediated immune response [22], which involves the uptake of HSP-peptide complexes by antigen-presenting cells (APCs) and the subsequent cross-presentation on MHC class I molecules to specific $\mathrm{CD}^{+} \mathrm{T}$-cell populations [22] . In a study of NPC, the reconstituted complex with mycobacterial Hsp70 and EBV LMP2A-derived peptides has been shown with ability to elicit peptide-specific cytotoxic T-lymphocyte responses and anti-tumor immune cells [23]. Hsp70, therefore, appears to play dual roles in the progression of tumors. To date, however, the expression dynamics of Hsp70 tissues and the relevance to the clinicopathologic and prognostic significance have not been clearly investigated in NPC.

Here, we first examined Hsp70 expression patterns with immunohistochemical (IHC) staining of 507 paraffin-embedded NPC tumor tissues. Secondly, we analyzed the correlation between the Hsp70 expression level and the clinical factors and outcomes for NPC patients. Furthermore, we evaluated the possible role of Hsp70 in the progression of NPC tumors.

\section{Materials and methods}

\section{Patients and clinical tissue samples}

In this study, 507 NPC specimens were collected at the Sun Yat-Sen University Cancer Center, Guangzhou, China, between January 2001 and December 2003. The cases were selected based on the following criteria: pathologically confirmed diagnosis of nasopharyngeal carcinoma with biopsy specimens available for tissue microarray (TMA) construction, no previous malignant disease or second primary tumor and no history of radiotherapy, chemotherapy or surgical treatment. All selected samples comprised at least $70 \%$ carcinoma tissue as determined by frozen section examination. The patient characteristics are shown in Table 1. The clinical stage was defined according to the 1992 NPC staging system of China [24]. All patients were treated with standard curative radiotherapy with or without
Table 1 Characteristics of nasopharyngeal carcinoma patients $(n=507)$

Characteristic Nasopharyngeal carcinoma patients: $n$
(\%)

\begin{tabular}{ll}
\hline Sex & \\
\hline Female & $126(24.9)$ \\
\hline Male & $381(75.1)$ \\
\hline Age (years) & $46(19-78)$ \\
\hline Median (range) & $46.38 \pm 11.065$ \\
\hline Mean \pm SD & \\
\hline Clinical stage & $140(27.7)$ \\
\hline I-II & $367(72.3)$ \\
\hline III-IV & $310(61.1)$ \\
\hline Progression & $197(38.9)$ \\
\hline No & \\
\hline Yes & $341(67.3)$ \\
\hline Death & $166(32.6)$ \\
\hline No & $68(3-114)$ \\
\hline Yes & $60.81(25.4)$ \\
\hline Follow-up time (months) & \\
\hline Median (range) & $129(25.4)$ \\
\hline Mean \pm SD & $13(2.6)$ \\
\hline WHO histological & $1(0.2)$ \\
\hline classification & \\
\hline NKUC & \\
\hline NKDC & \\
\hline KSCC & \\
\hline Missing & \\
\hline SD, standad devar & \\
\hline
\end{tabular}

SD, standard deviation; WHO, World Health Organization; NKUC, nonkeratinizing undifferentiated carcinoma; NKDC, non-keratinizing differentiated carcinoma; KSCC, keratinizing squamous cell carcinoma.

chemotherapy. The follow-up period was defined as the time from diagnosis to the date of death or to the time of censure if the patient was still alive. Disease progression was defined as progressive disease after primary treatment or recurrence (local progression) and/or the development of new distant metastases (distant progression). The Institute Research Medical Ethics Committee of Sun Yat-Sen University granted approval for this study.

\section{Tissue microarray construction}

The paraffin-embedded specimens were included in the previously constructed tissue microarray (TMA) and the procedures for the TMA construction have been described previously [25]. Briefly, the paraffin-embedded tissue blocks and the corresponding histological H\&Estained slides were overlaid for tissue TMA sampling. Duplicate $1.0 \mathrm{~mm}$ diameter cylinders were punched from representative tumor areas of an individual donor tissue block and re-embedded into a recipient paraffin 
block at a defined position using a tissue array instrument (Beecher Instruments, Silver Spring, MD).

\section{Immunohistochemistry (IHC) and evaluation}

IHC was performed to examine the Hsp70 and HLA-A expression in nasopharyngeal carcinoma tissues, by using primary antibodies against Hsp70 (1:200 dilution; sc-24, Santa Cruz, USA) and HLA-A (1:300 dilution; sc-23446, Santa Cruz, USA), and according to the previous procedures [25]. The IHC results were evaluated and scored independently by three pathologists without knowledge of the patient's clinicopathological outcomes. A semi-quantitative estimate was made using a composite score obtained by adding the intensity of the staining and the relative abundance of positive cells. The intensity was graded as 0 (negative), 1 (weakly positive), 2 (moderately positive) or 3 (strongly positive). The abundance of positive cells was graded from 0 to $4(0,<5 \%$ positive cells; 1 , 5-25\%; 2, 26-50\%; 3, 51-75\%; 4, 76-100\%). The pathologists were in agreement for approximately $82.5 \%$ of the cases, which demonstrated that this scoring method was highly reproducible. If at least 2 scores were in agreement, the consensus value was selected. If all three pathologists proposed different results, the pathologists reached a consensus.

\section{Selection of cutoff score}

Receiver operating characteristic (ROC) curve analysis was performed to determine the cutoff score for a "high expression" designation with the 0,1-criterion implemented in SPSS software [25]. First, the clinicopathological characteristics were dichotomized as following groups: $\mathrm{T}$ classification (T1-T2 versus T3-T4), N classification (N0 versus N1-N3), clinical stage (I-II versus III-IV), cancer progression (Yes versus No) and survival status (death due to NPC versus censored). Second, the expression scores for Hsp70 were trained in the ROC analysis. The cutoff score is the point on the curve that has both maximum sensitivity and specificity [25].

\section{Statistical analyses}

Statistical analyses were performed with the SPSS statistical software package (standard version 16.0; SPSS, Chicago, IL). Associations between the Hsp70 expression and clinicopathological parameters were assessed using a Chi-Square test. Associations between the Hsp70 expression patterns and HLA-A levels were examined with Pearson correlation and independent $t$-test. Survival curves were plotted by Kaplan-Meier analysis and compared by the log-rank test. The Cox proportional hazards regression model was employed to identify independent prognostic factors. Difference was considered as significant if the $P$-value from a two-tailed test was less than 0.05 .

\section{Results}

Patient characteristics

Among the 507 patients, 381 (75.1\%) were male, and the median age was 46 years (ranging 17-78 years). One hundred and twenty-nine tumors (25.4\%) were diagnosed as non-keratinizing differentiated carcinoma (NKDC), and 364 tumors $(71.8 \%)$ were diagnosed as non-keratinizing undifferentiated carcinoma (NKUC), 13 tumors (2.6\%) were categorized as keratinizing squamous cell carcinoma (KSCC). One hundred and forty patients $(27.7 \%)$ were at stages I or II, and 367 patients $(72.3 \%)$ were at stages III or IV. The median follow-up time was 60.81 months (ranging 3-114 months). Of the total number of patients, 166 (32.6\%) died, and 197 (38.9\%) experienced disease progression during the five-year follow-up. The detailed clinical information is shown in Table 1.

\section{Different expression patterns of Hsp70 in NPC}

A total of 507 NPC cases with five-year follow-up information were examined for the Hsp70 expression. Specific Hsp70 staining was detected in the tumor nest cells but not in the stroma. Interestingly, different staining patterns of Hsp70 were observed in NPC tumor tissues (Figure $1 \mathrm{~A}, \mathrm{~B}$ ), with spatial difference among nuclear, membrane and cytoplasm. Therefore, the membranal and the cytoplasmic expression or nuclear abundance of Hsp70 were separately scored and evaluated for their predictive values in NPC.

Selection of the cutoff score for high expression of Hsp70 ROC curve analysis showed that both extra-nucleic and nucleic abundance of Hsp70 have some sort of predictive values in NPC, with maximum area under curve (AUC) reaching 0.620 and 0.577 for Hsp70 abundance in the two locations, respectively (Figure $2 \mathrm{E}$ and J, black arrowed). The points in curves with maximum specificity and sensitivity were treated as cutoff points for high expression of Hsp70. For survival analysis the cutoff score for membranal and cytoplasmic expression of Hsp70 was 3.5, and the cutoff score for the nuclear expression of Hsp70 was defined as 4.5 (Table 2). As a result, tumors designated as low expression of Hsp70 are those with the scores below or equal to the cutoff score, while tumors of high expression are those with scores above the cutoff score.

\section{Association of Hsp70 expression patterns with clinicopathologic features}

High membranal and cytoplasmic expression levels of Hsp70 were detected in 226/507 (44.6\%) NPC tissues, and high nuclear abundance of Hsp70 were observed in 

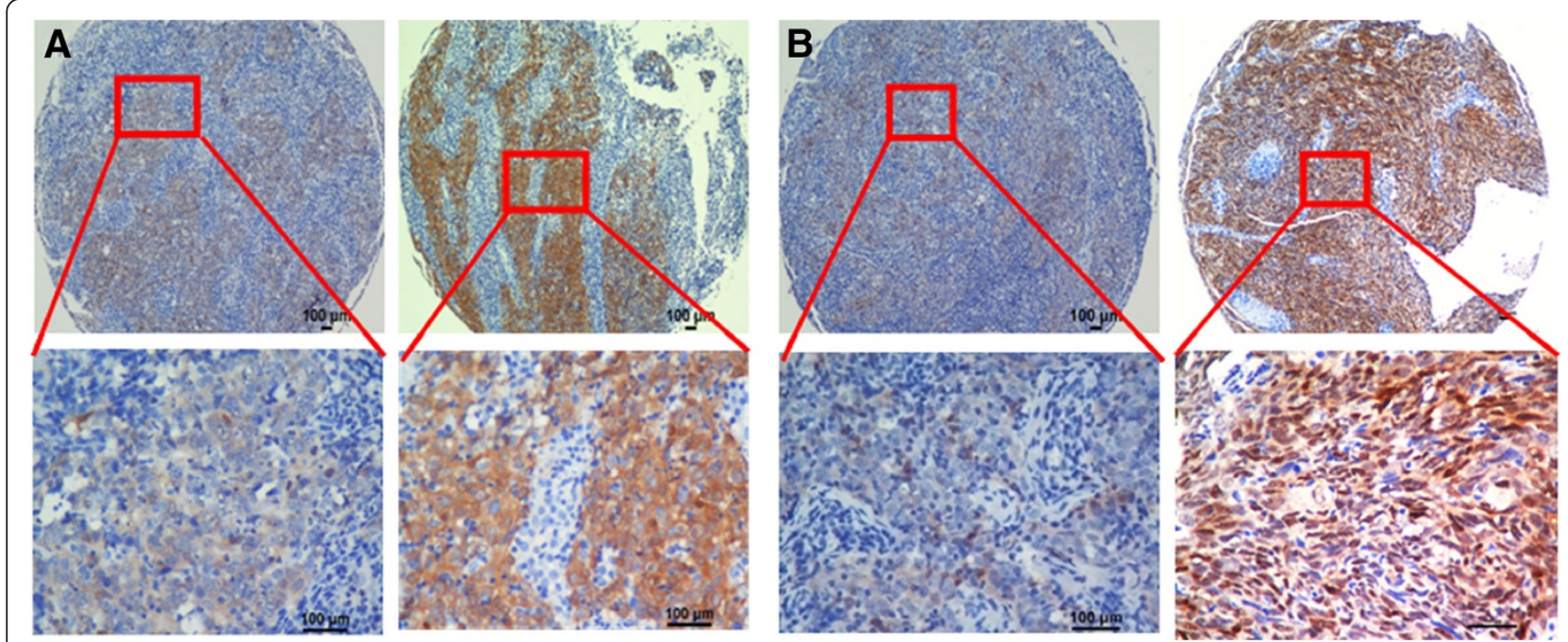

Figure 1 Different expression patterns of Hsp70 in NPC tumor tissues. A, Low and high expression levels of Hsp70 in the membrane and cytoplasm in the TMA are shown under both low and high magnification. B, Low and high levels of Hsp70 nuclear abundance in the TMA are shown under both low and high magnification. Scale bars, $100 \mu \mathrm{m}$.

137/507 (27.1\%) NPC tissues. The frequencies of different Hsp70 expression patterns with respect to several clinicopathologic features are detailed in Table 3. Interestingly, we found that high membranal and cytoplasmic expression levels of Hsp70 were significantly negatively correlated with tumor T classification, recurrence or metastasis and advanced clinical stage $(P<0.01$, Table 3$)$, but no significant association was observed between Hsp70 membranal and cytoplasmic expression levels and other clinicopathologic features such as sex, age and

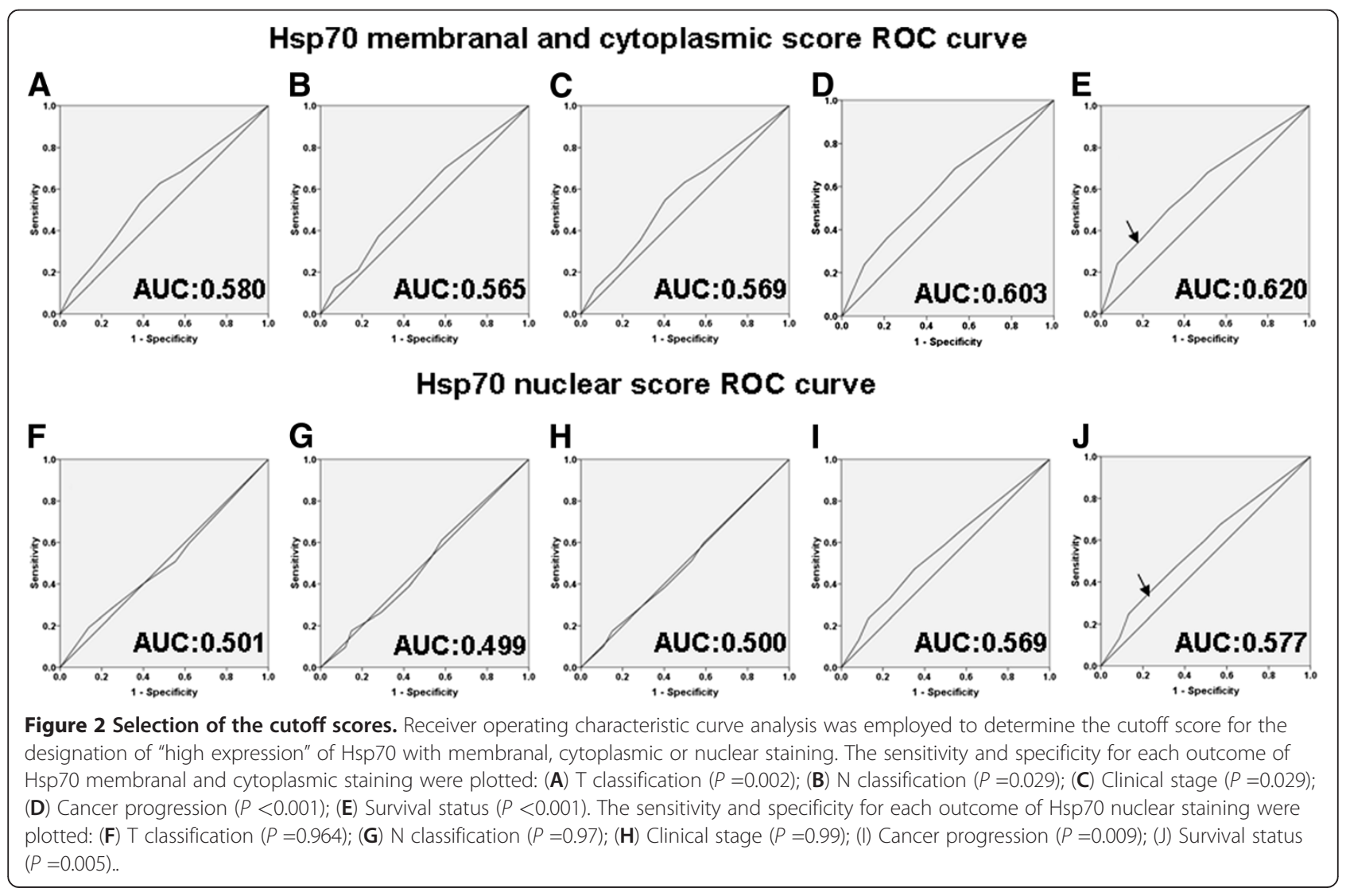


Table 2 The corresponding cutoff score of Hsp70 expression patterns for each clinicopathological feature according to ROC curve analysis

\begin{tabular}{|c|c|c|c|c|}
\hline \multirow[t]{2}{*}{ Feature } & \multicolumn{2}{|c|}{$\begin{array}{l}\text { Hsp70 membranal } \\
\text { and cytoplasmic staining }\end{array}$} & \multicolumn{2}{|c|}{$\begin{array}{l}\text { Hsp70 nuclear } \\
\text { staining }\end{array}$} \\
\hline & Cutoff score & $P$ value & Cutoff score & $P$ value \\
\hline T classification & 3.5 & 0.002 & 5.5 & 0.964 \\
\hline N classification & 1 & 0.029 & 3.5 & 0.97 \\
\hline Clinical stage & 3.5 & 0.029 & 5.5 & 0.99 \\
\hline Cancer progression & 1 & $<0.001$ & 3.5 & 0.009 \\
\hline Survival status & 3.5 & $<0.001$ & 4.5 & 0.005 \\
\hline
\end{tabular}

Hsp70, heat shock protein 70; ROC, receiver operating characteristic.

$\mathrm{N}$ classification $(P>0.05$, Table 3$)$. In contrast, high abundance of nucleic Hsp70 was positively correlated with tumor recurrence or metastasis $(P<0.05$, Table 3$)$, but not with other clinicopathologic features such as tumor $\mathrm{T}$ and $\mathrm{N}$ classification, sex, age and clinical stage $(P>0.05$, Table 3$)$.

\section{Association between the Hsp70 expression pattern and survival}

Due to the finding that the expression of Hsp70 was correlated with recurrence or metastasis, its correlation with survival was examined. The 5-year overall survival rate of the 507 NPC patients was $66.18 \%$. The low and high Hsp70 expression groups were divided by the cutoff value as previously reported $[25,26]$. For these 507 NPC patients, Kaplan-Meier and log-rank test analyses indicated that patients with high Hsp70 membranal and cytoplasmic expression levels had a significantly better overall survival (OS; 5-year survival rates, $76.1 \%$ vs. $60.1 \%, P=0.001$, Figure $3 \mathrm{~A}$ ) and disease-free survival (DFS; 5 -year survival rates, $68.6 \%$ vs. $55.2 \%, P=0.001$, Figure 3B) than patients with low Hsp70 expression levels. Further stratification analysis by clinical stage revealed that the Hsp70 membranal and cytoplasmic expression levels were not related to OS and DFS in the early stages (Additional file 1: Figure S1A and B); however, for the patients at late-stage, high membranal and cytoplasmic expression levels of Hsp70 were correlated with improved OS (5-year survival rates, $66.7 \%$ vs. $52.3 \%, P=0.006$, Additional file 1: Figure S1C) and DFS (5-year survival rates, $61.3 \%$ vs. $47.7 \%, P=0.007$, Additional file 1: Figure S1D).

Moreover, the correlation between Hsp70 abundance in the nuclei and survival was tested. Surprisingly, we found that high nuclear abundance of Hsp70 correlated with worse OS (5-year survival rates, $57.7 \%$ vs. $70.8 \%$, $P=0.001$, Figure $3 \mathrm{C}$ ) and DFS (5-year survival rates, $52.6 \%$ vs. $64.3 \%, P=0.005$, Figure $3 \mathrm{D}$ ) than did low levels of nuclear abundance of Hsp70. Subsequent stratification analysis according to clinical stages revealed that the nucleic abundance of $\mathrm{Hsp70}$ is consistently correlated with worse OS (5-year survival rates, $47 \%$ vs. $62.3 \%, P=0.001$, Additional file 2: Figure S2C) and DFS

Table 3 Association of different Hsp70 expression patterns and clinicopathological characteristics in NPC patients

\begin{tabular}{|c|c|c|c|c|c|c|}
\hline \multirow[t]{2}{*}{ Characteristics } & \multicolumn{2}{|c|}{ Hsp70 membranal and cytoplasmic staining } & \multirow{2}{*}{$\begin{array}{l}P \\
\text { value }\end{array}$} & \multicolumn{2}{|c|}{ Hsp70 nuclear staining } & \multirow{2}{*}{$\begin{array}{l}P \\
\text { value }\end{array}$} \\
\hline & $\begin{array}{l}\text { low expression } \\
(n=281)\end{array}$ & $\begin{array}{l}\text { high expression } \\
(\mathrm{n}=226)\end{array}$ & & $\begin{array}{l}\text { low expression } \\
(\mathrm{n}=370)\end{array}$ & $\begin{array}{l}\text { high expression } \\
(n=137)\end{array}$ & \\
\hline Age, years & & & 0.751 & & & 0.857 \\
\hline$<46$ & 131 & 116 & & 176 & 71 & \\
\hline$>=46$ & 145 & 115 & & 188 & 72 & \\
\hline Sex & & & 0.828 & & & 0.715 \\
\hline Male & 209 & 170 & & 275 & 104 & \\
\hline Female & 72 & 56 & & 94 & 34 & \\
\hline Tumor stage & & & 0.001 & & & 0.401 \\
\hline $\mathrm{T} 1+\mathrm{T} 2$ & 96 & 109 & & 153 & 51 & \\
\hline $\mathrm{T} 3+\mathrm{T} 4$ & 186 & 116 & & 217 & 86 & \\
\hline Lymphoid Nodal(N) state & & & 0.061 & & & 0.468 \\
\hline No & 64 & 69 & & 94 & 40 & \\
\hline N1-3 & 217 & 157 & & 276 & 97 & \\
\hline Recurrence or metastasis & & & 0.002 & & & 0.016 \\
\hline Yes & 126 & 71 & & 132 & 65 & \\
\hline No & 155 & 155 & & 238 & 72 & \\
\hline TNM clinical stage & & & 0.005 & & & 0.900 \\
\hline $1+\|$ & 63 & 76 & & 102 & 37 & \\
\hline$I I I+I V$ & 218 & 150 & & 268 & 100 & \\
\hline
\end{tabular}

Hsp70, heat shock protein 70 . 

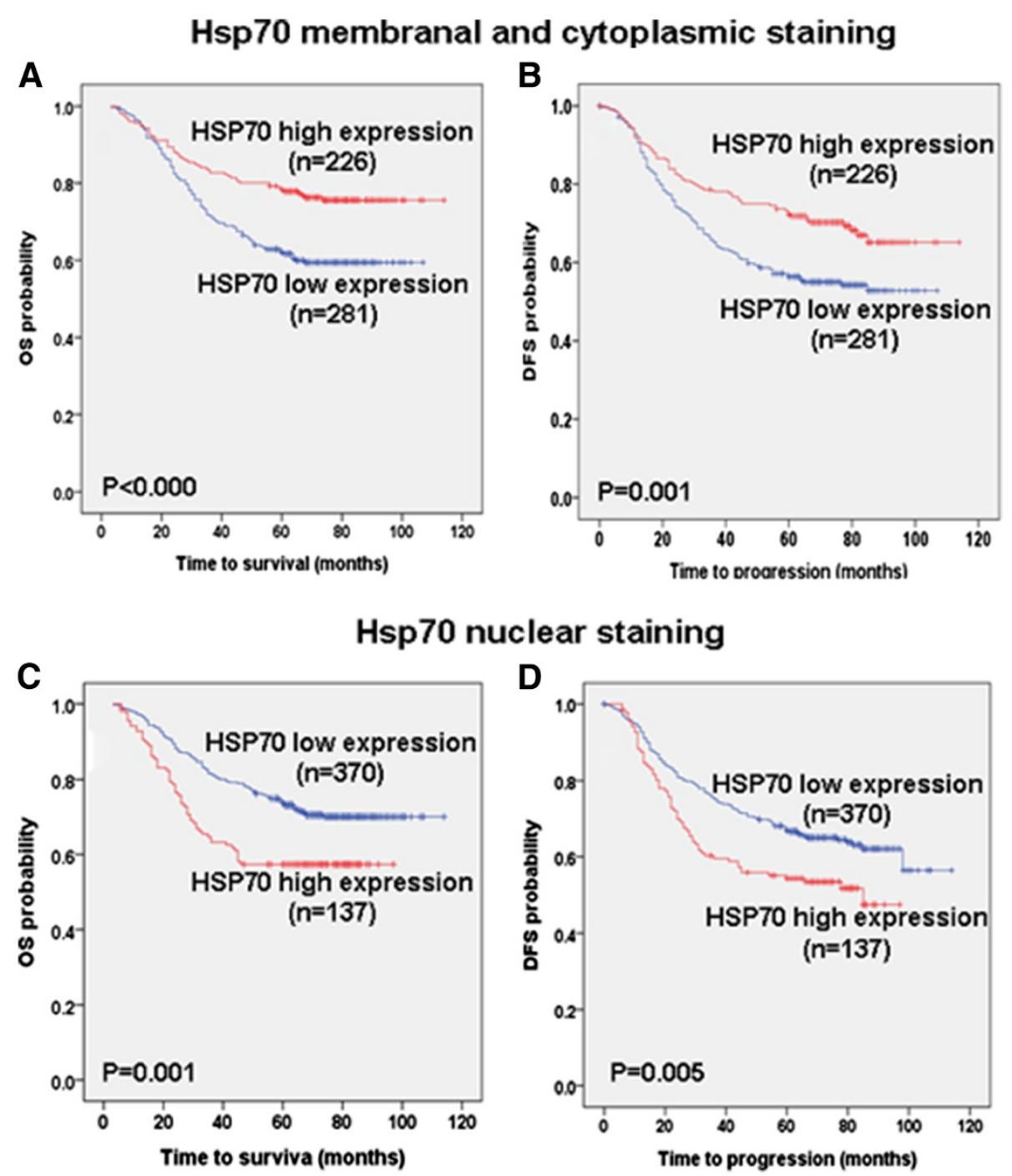

Figure 3 The association of different Hsp70 expression patterns with NPC patient survival. TMA analyses of a cohort of 507 NPC patients diagnosed at M0 were conducted. A and $\mathbf{B}$, high Hsp70 membranal and cytoplasmic expression levels were significantly positively associated with overall survival $(O S, P=0.001)$ and disease-free survival (DFS, $P=0.001)$ in all NPC patients. $\mathbf{C}$ and $\mathbf{D}$, high Hsp70 nuclear abundance were significantly negatively associated with overall survival $(O S, P=0.001)$ and disease-free survival (DFS, $P=0.005)$ in NPC patients.

(5-year survival rates, $45.0 \%$ vs. $56.3 \%, P=0.010$, Additional file 2: Figure S2D); however, no correlation was found for sample in the early stages (Additional file 2: Figure 2A and B).

\section{Association between clinicopathologic features, Hsp70 expression patterns and NPC patient survival: univariate and multivariate survival analyses}

To confirm the representative of the present NPC cohort, we tested the associations of some well-known prognostic indicators with survival. The univariate Cox proportional hazard regression analysis showed that the clinicopathologic parameters including $\mathrm{T}$ classification, $\mathrm{N}$ classification, recurrence or metastasis, and clinical stage are each significantly associated with survival
$(P<0.001$; Table 4), which is consistent with the previous findings. Moreover, the assessment of NPC patient survival revealed that high membranal and cytoplasmic expression levels of Hsp70 were significantly correlated with improved overall survival $(P<0.001$; Table 4), whereas high nuclear abundance of Hsp70 were significantly correlated with poor overall survival $(P=0.001$, Table 4). In addition, the age was also associated with survival $(P=0.002)$.

Independency tests were carried out among the prognostic factors, including the different expression patterns of Hsp70 and other significant clinicopathologic features (age, $\mathrm{T}$ classification, $\mathrm{N}$ classification, distant metastasis and clinical stage), under a multivariate Cox proportional hazards regression analysis (Table 4). We found 
Table 4 Univariate and multivariate Cox regression analyses of different prognostic variables for NPC patients

\begin{tabular}{|c|c|c|c|}
\hline Variable & Subset & Hazard ratio $(95 \%) \mathrm{Cl}$ & $P$ value \\
\hline \multicolumn{4}{|l|}{ Univariate analysis $(n=507)$} \\
\hline Hsp70 membranal and cytoplasmic staining & low vs. high & $0.540(0.390-0.747)$ & $<0.001$ \\
\hline Hsp70 nucleus staining & low vs. high & $1.708(1.241-2.351)$ & 0.001 \\
\hline Age & $<46$ vs. $>=46$ & $1.644(1.202-2.249)$ & 0.002 \\
\hline Sex & male vs. female & $0.827(0.574-1.192)$ & 0.308 \\
\hline T stage & $\mathrm{T} 1+\mathrm{T} 2$ vs. $\mathrm{T} 3+\mathrm{T} 4$ & $3.149(2.159-4.594)$ & $<0.001$ \\
\hline N stage & No vs. N1 + N2 + N3 & $2.474(1.592-3.846)$ & $<0.001$ \\
\hline Recurrence or metastasis & No vs. Yes & 548.914 (76.728-3.927E3) & $<0.001$ \\
\hline Clinical stage & I+II vs. III+IV & $6.034(3.352-10.862)$ & $<0.001$ \\
\hline \multicolumn{4}{|l|}{ Multivariate analysis $(n=507)$} \\
\hline Hsp70 cytoplasmic and membranal staining & low vs. high & $0.529(0.360-0.778)$ & 0.001 \\
\hline Hsp70 nuclear staining & low vs. high & $2.601(1.785-3.789)$ & $6.41 \mathrm{E}-07$ \\
\hline Clinical stage & $I+\|$ vs. $I I I+I V$ & $3.641(1.623-8.170)$ & 0.002 \\
\hline
\end{tabular}

$\mathrm{Cl}$, confidence interval; WHO, World Health Organization; Hsp70, heat shock protein 70.

that high membranal and cytoplasmic expression levels of Hsp70 were independent favorable factors for overall patient survival (hazard ratio: $0.529 ; 95 \%$ confidence interval: $0.360-0.778 ; P=0.001)$, whereas high nuclear levels of Hsp70 were an independent risk factor for overall patient survival (hazards ratio: 2.601; 95\% confidence interval: $1.785-3.789 ; P<0.001)$. Among the other variables, clinical stage was also found to be an independent prognostic predictor of overall survival (Table 4).

\section{Correlation between the Hsp70 abundance and the expression of HLA-A}

In light of the involvement of Hsp70 in the antigen presentation process, which HLA-A plays important role, we further investigated the correlation between its abundance and HLA-A expression. The results showed a markedly positive correlation between the membranal and cytoplasmic expression level of Hsp70 and the expression of HLA-A in NPC tissues (Figure 4A) (Pearson Correlation =0.255). In the 226 NPC samples with high expression of membranal and cytoplasmic Hsp70, the average HLA-A score was 3.82, which was significantly higher than that (2.81) found in the remaining 281 NPCs with low expression of membranal and cytoplasmic Hsp70 $(P<0.001$, independent sample $t$ test; Figure $4 \mathrm{~B})$. On the other hand, although low expression of HLA-A was found in NPC tumors with abundant nucleic Hsp70 (Pearson Correlation $=-0.145$ ), the correlation didn't reach a statistically significance $(p=0.092)$.

\section{Discussion}

As a member of the HSP family, Hsp70 has been considered as cancer relevant protein. On one hand, its high
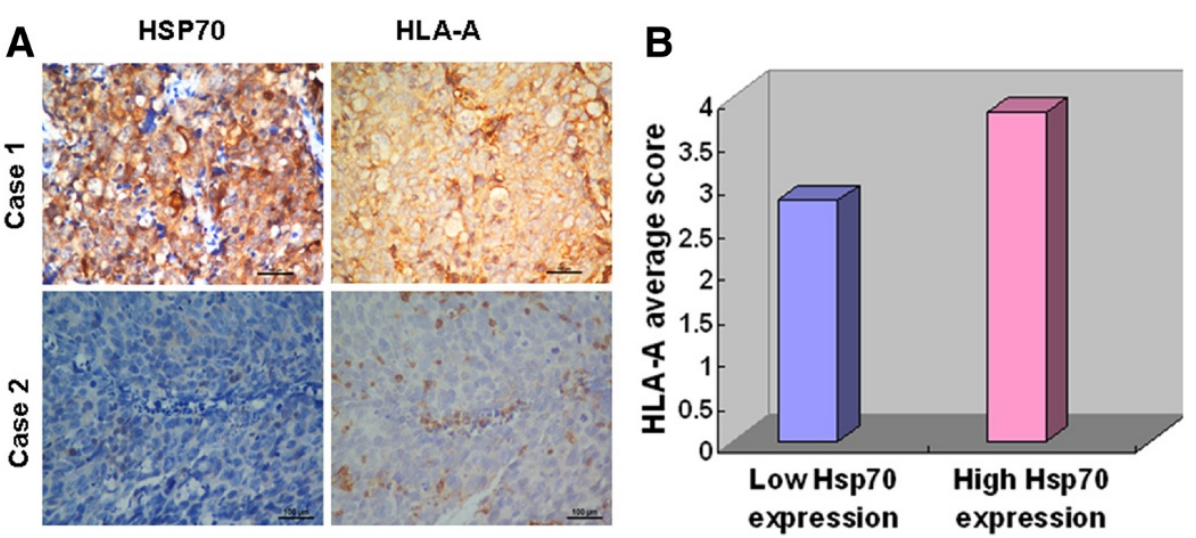

Figure 4 Correlation between expression levels of Hsp70 and the level of HLA-A in NPC tissues. A, continuous sections of human NPC tissue were subjected to IHC staining with antibodies against Hsp70 and HLA-A. The high membranal and cytoplasmic expression levels of Hsp70 in the tumor tissue in case 1 were accompanied by an elevated level of HLA-A. Conversely, the low membranal and cytoplasmic expression levels of Hsp70 in the tumor tissue of case 2 were accompanied by a low level of HLA-A. Scale bars $=100 \mu \mathrm{m}$. B, in 226 NPC cases with high membranal and cytoplasmic expression levels of Hsp70, an average HLA-A score was 3.82 (right column), an average score that was significantly higher than that (2.81) of the 281 NPCs with low expression levels of Hsp70 (left column, $P<0.001$, independent sample $t$-test). 
expression has been demonstrated in malignant tumors such as breast cancer [27], lung cancer [28], oral squamous cell carcinoma [29] and prostate cancer [30]; and moreover, its overexpression has been correlated with poor prognosis and resistance to therapy [27-30]. These suggest that Hsp70 might promote somehow tumor development. On the other hand, previous studies have shown that Hsp70 acts as chaperone for presenting tumor antigens to activate immune response [20,21], and mediate anti-cancer immunity [31], suggesting the opposite role of Hsp70 to tumor development. The mechanism underlying the dual roles of Hsp70 to tumorigenesis is still unclear.

In the present study, the expression of $\mathrm{Hsp70}$ was determined by IHC in a large cohort of NPC tissues using a NPC-TMA with follow-up data. Among the 507 patients, we noted distinct nuclear, membranal and cytoplasmic localization of Hsp70 in NPC tissues. Interestingly, we observed that distinct Hsp70 expression patterns correlated with different clinical outcomes. High membranal and cytoplasmic expression levels of Hsp70 predicted an improved survival rate, whereas high nuclear abundance of Hsp70 was correlated with a poor survival rate. These findings suggest that Hsp70 might be a favorable prognostic indicator, which could be used in the search of novel treatment to improve survival for the patient with poor predicted outcome.

More importantly, further correlation analyses revealed that high membranal and cytoplasmic expression levels of Hsp70 in NPCs were negatively associated with tumor T classification, $\mathrm{N}$ classification, recurrence and metastasis, advanced clinical stage and histological type. In contrast, high nuclear abundance of Hsp70 was positively correlated with tumor recurrence, metastasis and histological type. These results suggested that membranal and cytoplasmic Hsp70 might play an anti-tumor role, whereas nuclear Hsp70 may provide a selective advantage in the NPC tumorigenic processes.

NPC is a malignancy widely known as Epstein-Barr virus (EBV)-related, and thus many immune-related genes have been examined for the association with NPC development. Among them, human leukocyte antigen (HLA) has been extensively studied, considering the capability of HLA to present antigen to cytotoxic $\mathrm{T}$ cells and, thus, trigger the host immune response against viral infection. Genetic studies have shown that some HLA alleles such as HLAA*0203 and HLA-A*0207 are risk alleles while HLAA*1101 is a protective allele for NPC [32]. Moreover, the genome-wide expression profiling study showed that the expression of MHC class I molecules were inhibited by EBV genes in NPC tumors [33]. HLA restricted EBV variants, which lose T-cell epitopes have been demonstrated in NPC [34,35]. In addition, loss of HLA locus in NPC tumor genome was observed (unpublished data). These findings consistently support the contribution of HLA to NPC development. In this study, HLA-A expression was found in NPC tumors, and was positively correlated with the membranal and cytoplasmic expression levels of Hsp70, which are in agreement with previous studies [36,37]. Hsp70 family members are known as facilitators of immune responses by interacting with receptor on antigen-presenting cells leading to Hsp70-peptide uptake and antigen cross priming [38]. Moreover, As a chaperone, Hsp70 has the abilities to induce strong antiviral T-cell responses [39] and to elicit LMP2A-specific IFN- $\gamma$-producing cells and rousted cytotoxic T lymphocytes (CTLs) in vitro and in vivo [40]. Furthermore, it has been shown that HSP70 significantly increase $\mathrm{MHC}$ class I cell surface expression and antigen presentation on melanoma B16 cells $[41,42]$. Therefore, the membranal and cytoplasmic Hsp70 might play a role in the HLA related immune response, so as to exhibit the antitumor effect on NPC. Indeed, the application of Hsp70 for cancer therapy as a tumor-antigen carrier has been extensively investigated in cancers [22,43-47], including NPC [23].

On the other hand, we found high Hsp70 abundance in the nuclei in NPC tissues, which positively correlated with tumor recurrence, distant metastasis and a poor survival rate. Moreover, in NPC tumors with Hsp70 abundant in the nuclear, we found low abundance of HLA-A, even though the correlation didn't reach a statistically significance. These findings suggested that nucleic localization of Hsp70 might decrease HLA-A cell surface expression and antigen presentation, and play tumorigenic role in NPC. This is supported by previous report that Hsp70 can effectively inhibit tumor cell death induced by several stresses such as heat shock, hypoxia and oxidative stress [48]. Moreover, studies have shown that Hsp70 can translocate from cytoplasm to nucleus or nucleoli under heat-stress conditions and plays a protective role against stress-mediated apoptosis and DNA damage by co-localizing with DNA repair proteins, $[49,50]$, and thus increases tumor cell survival.

\section{Conclusion}

Here, we described the distinct expression patterns of Hsp70 in human NPC tissues, which might play different roles during NPC tumor cell progression, could predict different patient outcomes for the first time. Furthermore, our data suggest that the different localization of Hsp70 could be molecular targets for the development of novel therapeutic strategies.

\section{Additional files}

Additional file 1: Figure S1. Association of Hsp70 membranal and cytoplasmic expression levels with survival of NPC patients at different 
stages. A and B, no significant differences in five-year OS and DFS rates were found between low and high levels of Hsp70 membranal and cytoplasmic expression levels in NPC patients with early stage disease (stage I - II). C and D, high Hsp70 membranal and cytoplasmic expression levels were significantly positively associated with overall survival (OS, $P=0.006)$ and disease-free survival (DFS, $P=0.007$ ) in NPC patients with late-stage disease (stage III-IV).

Additional file 2: Figure S2. Association of Hsp70 nuclear abundance with survival of NPC patients at different stages. A and B, no significant differences in five-year OS and DFS rates were found between low and high levels of Hsp70 nuclear abundance in NPC patients with early stage disease (stage I - II). C and D, high Hsp70 nuclear abundance were significantly positively associated with the survival $(O S, P=0.006)$ and disease-free survival (DFS, $P=0.007$ ) in NPC patients with late-stage disease (stage III-IV).

\section{Abbreviations}

Hsp70: heat shock protein 70; IHC: immunohistochemistry;

NPC: nasopharyngeal carcinoma; APCs: antigen-presenting cells; TMA: tissue microarray; ROC: receiver operating characteristic; NKDC: non-keratinizing differentiated carcinoma; NKUC: non-keratinizing undifferentiated carcinoma; KSCC: keratinizing squamous cell carcinoma; AUC: areas under the curve.

\section{Competing interests}

The authors declare that they have no competing interests.

\section{Acknowledgements}

This study was supported partially by the National High Technology Research and Development Program of China (863 Program)

(2012AA02A501), the State Basic Research Development Program of China (973 Program) (No. 2011CB504805 and 2011CB504300).

\section{Author details}

'State Key Laboratory of Oncology in South China, Cancer Center, Sun Yat-Sen University, 651\# Dongfeng Road East, Guangzhou 510060 China. ${ }^{2}$ Cancer Research Institute, University of South China, Hengyang China. ${ }^{3}$ Department of Molecular Diagnostics, Cancer Center, Sun Yat-Sen University, 651\# Dongfeng Road East, Guangzhou 510060 China. ${ }^{4}$ Wadsworth Center, New York State Department of Health, Albany NY, USA.

\section{Authors' contributions}

$\mathrm{MB}$ conducted the study, participated in the data collection, performed most experiments, and wrote the initial draft and revised the manuscripts. XP and JX collected the preliminary data, and helped to perform some experiments. $H Q, C C$ and TB participated in the study design and interpretation of the data. RJ, YL, QS, HY, LZ and SF undertaking immunohistochemistry work. JX, $J Y$ and $Y X$ study coordination and revision of the paper. All authors read and approved the final manuscript.

Received: 17 December 2011 Accepted: 16 May 2012

Published: 16 May 2012

\section{References}

1. Wei WI, Sham JS: Nasopharyngeal carcinoma. Lancet 2005, 365 (9476):2041-2054.

2. Chang ET, Adami HO: The enigmatic epidemiology of nasopharyngeal carcinoma. Cancer Epidemiol Biomarkers Prev 2006, 15(10):1765-1777.

3. Klibi J, Niki T, Riedel A, Pioche-Durieu C, Souquere S, Rubinstein E, Le Moulec S, Guigay J, Hirashima M, Guemira F, Adhikary D, Mautner J, Busson P: Blood diffusion and Th1-suppressive effects of galectin-9-containing exosomes released by Epstein-Barr virus-infected nasopharyngeal carcinoma cells. Blood 2009, 113(9):1957-1966.

4. Baujat B, Audry H, Bourhis J, Chan AT, Onat H, Chua DT, Kwong DL, Al-Sarraf M, Chi KH, Hareyama M, Pignon JP, MAC-NPC Collaborative Group: Chemotherapy in locally advanced nasopharyngeal carcinoma: an individual patient data meta-analysis of eight randomized trials and 1753 patients. Int J Radiat Oncol Biol Phys 2006, 64(1):47-56.

5. Al-Sarraf M, LeBlanc M, Giri PG, Fu KK, Cooper J, Vuong T, Forastiere AA, Adams G, Sakr WA, Schuller DE, Ensley JF: Chemoradiotherapy versus radiotherapy in patients with advanced nasopharyngeal cancer: phase III randomized Intergroup study 0099. J Clin Oncol 1998, 16(4):1310-1317.

6. Langendijk JA, Leemans CR, Buter J, Berkhof J, Slotman BJ: The additional value of chemotherapy to radiotherapy in locally advanced nasopharyngeal carcinoma: a meta-analysis of the published literature. J Clin Oncol 2004, 22(22):4604-4612.

7. Chan SL, Ma BB: Novel systemic therapeutic for nasopharyngeal carcinoma. Expert Opin Ther Targets 2012, 16(Suppl 1):S63-S68.

8. Komatsu M, Tsukuda M, Matsuda H, Horiuchi C, Taguch T, Takahashi M, Nishimura G, Mori M, Niho T, Ishitoya J, Sakuma Y, Hirama M, Shiono O: Comparison of concurrent chemoradiotherapy versus induction chemotherapy followed by radiation in patients with nasopharyngeal carcinoma. Anticancer Res 2012, 32(2):681-686.

9. Patel SG, Shah JP: TNM staging of cancers of the head and neck: striving for uniformity among diversity. CA Cancer J Clin 2005, 55(6):242-258.

10. Ma BB, Chan AT: Recent perspectives in the role of chemotherapy in the management of advanced nasopharyngeal carcinoma. Cancer 2005, 103 (1):22-31.

11. Chua DT, Ma J, Sham JS, Mai HQ, Choy DT, Hong MH, Lu TX, Min HQ: Longterm survival after cisplatin-based induction chemotherapy and radiotherapy for nasopharyngeal carcinoma: a pooled data analysis of two phase III trials. J Clin Oncol 2005, 23(6):1118-1124.

12. Hockel M, Vaupel P: Biological consequences of tumor hypoxia. Semin Oncol 2001, 28(2 Suppl 8):36-41.

13. Cui X, YU ZY, Wang W, Zheng YQ, Liu W, Li LX: Co-Inhibition of HSP70/ HSP90 Synergistically Sensitizes Nasopharyngeal Carcinoma Cells to Thermotherapy. Integr Cancer Ther 2011 [Epub ahead of print].

14. Gehrmann M, Radons J, Molls M, Multhoff G: The therapeutic implications of clinically applied modifiers of heat shock protein 70 (Hsp70) expression by tumor cells. Cell Stress Chaperones 2008, 13(1):1-10.

15. Wei $Y Q$, Zhao X, Kariya $Y$, Teshigawara K, Uchida A: Inhibition of proliferation and induction of apoptosis by abrogation of heat-shock protein (HSP) 70 expression in tumor cells. Cancer Immunol Immunother 1995, 40(2):73-78.

16. Jaattela M, Wissing D, Kokholm K, Kallunki T, Egeblad M: Hsp70 exerts its anti-apoptotic function downstream of caspase-3-like proteases. EMBO 1998, 17(21):6124-6134.

17. Rerole AL, Jego G, Garrido C: Hsp70: anti-apoptotic and tumorigenic protein. Methods Mol Biol 2011, 787:205-230.

18. Tong YQ, Zhang ZJ, Liu B, Huang J, Liu H, Liu Y, Guo FJ, Zhou GH, Xie PL, Li YH, Zuo CH, Hu JY, Li GC: Autoantibodies as potential biomarkers for nasopharyngeal carcinoma. Proteomics 2008, 8(15):3185-3193.

19. Liao Q, Zhao L, Chen X, Deng Y, Ding Y: Serum proteome analysis for profiling protein markers associated with carcinogenesis and lymph node metastasis in nasopharyngeal carcinoma. Clin Exp Metastasis 2008, 25(4):465-476

20. Calderwood SK, Theriault JR, Gong J: How is the immune response affected by hyperthermia and heat shock proteins? Int J Hyperthermia 2005, 21(8):713-716

21. Srivastava PK: Immunotherapy for human cancer using heat shock protein-peptide complexes. Curr Oncol Rep 2005, 7(2):104-108.

22. Srivastava PK, Menoret A, Basu S, Binder RJ, McQuade KL: Heat shock proteins come of age: primitive functions acquire new roles in an adaptive world. Immunity 1998, 8(6):657-665.

23. Liu G, Yao K, Wang B, Zhou F, Chen Y, Li L, Chi J, Peng G: Reconstituted complexes of mycobacterial HSP70 and EBV LMP2A-derived peptides elicit peptide-specific cytotoxic T lymphocyte responses and anti-tumor immunity. Vaccine 2011, 29(45):7414-7423.

24. Min H, Hong M, Ma J, Zhang E, Zheng Q, Zhang J, Zhang F, Su Y, Qiu F: A new staging system for nasopharyngeal carcinoma in China. Int J Radiat Oncol Biol Phys 1994, 30(5):1037-1042.

25. Wang HY, Sun BY, Zhu ZH, Chang ET, To KF, Hwang JS, Jiang H, Kam MK Chen G, Cheah SL, Lee M, Liu ZW, Chen J, Zhang JX, Zhang HZ, He JH, Chen FL, Zhu XD, Huang MY, Liao DZ, Fu J, Shao Q, Cai MB, Du ZM, Yan LX, Hu CF, Ng HK, Wee JT, Qian CN, Liu Q, Ernberg I, Ye W, Adami HO, Chan AT, Zeng YX, Shao JY: Eight-Signature Classifier for Prediction of Nasopharnyngeal Carcinoma Survival. J Clin Oncol 2011, 29(34):4516-4525.

26. Cai MY, Tong ZT, Zhu W, Wen ZZ, Rao HL, Kong LL, Guan XY, Kung HF Zeng YX, Xie D: H3K27me3 Protein Is a Promising Predictive Biomarker of Patients' Survival and Chemoradioresistance in Human Nasopharyngeal Carcinoma. Mol Med 2011, [Epub ahead of print]. 
27. Boroughs LK, Antonyak MA, Johnson JL, Cerione RA: A unique role for heat shock protein 70 and its binding partner tissue transglutaminase in cancer cell migration. J Biol Chem 2011, 286(43):37094-37107.

28. Malusecka E, Krzyzowska-Gruca S, Gawrychowski J, Fiszer-Kierzkowska A, Kolosza Z, Krawczyk Z: Stress proteins HSP27 and HSP70i predict survival in non-small cell lung carcinoma. Anticancer Res 2008, 28(1B):501-506.

29. Thubashini M, Malathi N, Kannan L: Expression of heat shock protein70 in oral submucous fibrosis and oral squamous cell carcinoma: an immunohistochemical study. Indian J Dent Res 2011, 22(2):256-259.

30. Lu S, Tan Z, Wortman M, Dong Z: Regulation of heat shock protein 70-1 expression by androgen receptor and its signaling in human prostate cancer cells. Int J Oncol 2010, 36(2):459-467.

31. Zeng Y, Chen X, Larmonier N, Larmonier C, Li G, Sepassi M, Marron M, Andreansky S, Katsanis E: Natural killer cells play a key role in the antitumor immunity generated by chaperone-rich cell lysate vaccination. Int J Cancer 2006, 119(11):2624-2631.

32. Bei JX, Jia WH, Zeng YX: Familial and large-scale case-control studies identify genes associated with nasopharyngeal carcinoma. Semin Cancer Biol 2012, 22(2):96-106

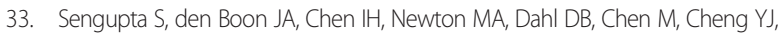
Westra WH, Chen CJ, Hildesheim A, Sugden B, Ahlquist P: Genome-wide expression profiling reveals EBV-associated inhibition of $\mathrm{MHC}$ class I expression in nasopharyngeal carcinoma. Cancer Res 2006, 66(16):7999-8006.

34. Tang YL, Lu JH, Cao L, Wu MH, Peng SP, Zhou HD, Huang C, Yang YX, Zhou YH, Chen Q, Li XL, Zhou M, Li GY: Genetic variations of EBV-LMP1 from nasopharyngeal carcinoma biopsies: potential loss of $T$ cell epitopes. Braz J Med Biol Res 2008, 41(2):110-116.

35. Lin JC, Cherng JM, Lin HJ, Tsang CW, Liu YX, Lee SP: Amino acid changes in functional domains of latent membrane protein 1 of Epstein-Barr virus in nasopharyngeal carcinoma of southern China and Taiwan: prevalence of an HLA A2-restricted 'epitope-loss variant'. J Gen Virol 2004, 85(7):2023-2034

36. Maranon C, Egui A, Carrilero B, Thomas MC, Pinazo MJ, Gascon J, Segovia M, Lopez MC: Identification of HLA-A *02:01-restricted CTL epitopes in Trypanosoma cruzi heat shock protein-70 recognized by Chagas disease patients. Microbes Infect 2011, 13(12-13):1025-1032.

37. Okochi M, Hayashi H, Ito A, Kato R, Tamura Y, Sato N, Honda H: Identification of HLA-A24-restricted epitopes with high affinities to Hsp70 using peptide arrays. J Biosci Bioeng 2008, 105(3):198-203.

38. Mizukami S, Kajiwara C, Tanaka M, Kaisho T, Udono H: Differential MyD88/ IRAK4 requirements for cross-priming and tumor rejection induced by heat shock protein 70-model antigen fusion protein. Cancer Sci 2012, Epub ahead of print.

39. Tischer S, Basila M, Maecker-Kolhoff B, Immenschuh S, Oelke M, Blasczyk R, Eiz-Vesper B: Heat shock protein 70/peptide complexes: potent mediators for the generation of antiviral T cells particularly with regard to low precursor frequencies. J Transl Med 2011, 9:175.

40. Liu G, Yao K, Wang B, Zhou F, Chen Y, Li L, Chi J, Peng G: Reconstituted complexes of mycobacterial HSP70 and EBV LMP2A-derived peptides elicit peptide-specific cytotoxic T lymphocyte responses and anti-tumor immunity. Vaccine 2011, 29(43):7414-7423.

41. Wells AD, Rai SK, Salvato MS, Band H, Malkovsky M: Hsp72-mediated augmentation of MHC class I surface expression and endogenous antigen presentation. Int Immunol 1998, 10(5):609-617.

42. Dressel R, Lubbers M, Walter L, Herr W, Gunther E: Enhanced susceptibility to cytotoxic T lymphocytes without increase of MHC class I antigen expression after conditional overexpression of heat shock protein 70 in target cells. Eur J Immunol 1999, 29(12):3925-3935.

43. Kumar S, Deepak P, Acharya A: Autologous Hsp70 immunization induces anti-tumor immunity and increases longevity and survival of tumorbearing mice. Neoplasma 2009, 56(3):259-268.

44. Tamura Y, Peng P, Liu K, Daou M, Srivastava PK: Immunotherapy of tumors with autologous tumor-derived heat shock protein preparations. Science 1997, 278(5335):117-120.

45. Srivastava PK: Immunotherapy of human cancer: lessons from mice. Nat Immunol 2000, 1(5):363-366.

46. Parmiani G, Testori A, Maio M, Castelli C, Rivoltini L, Pilla L, Belli F, Mazzaferro V, Coppa J, Patuzzo R, et al: Heat shock proteins and their use as anticancer vaccines. Clin Cancer Res 2004, 10(24):8142-8146.

47. Nishikawa M, Otsuki T, Ota A, Guan X, Takemoto S, Takahashi Y, Takakura Y: Induction of tumor-specific immune response by gene transfer of
Hsp70-cell-penetrating peptide fusion protein to tumors in mice. $\mathrm{Mol}$ Ther 2010, 18(2):421-428.

48. Rohde M, Daugaard M, Jensen MH, Helin K, Nylandsted J, Jaattela M: Members of the heat-shock protein 70 family promote cancer cell growth by distinct mechanisms. Genes Dev 2005, 19(5):570-582.

49. Welch WJ, Feramisco JR: Nuclear and nucleolar localization of the 72,000dalton heat shock protein in heat-shocked mammalian cells. J Biol Chem 1984, 259(7):4501-4513.

50. Kotoglou P, Kalaitzakis A, Vezyraki P, Tzavaras T, Michalis LK, Dantzer F, Jung $J U$, Angelidis C: Hsp70 translocates to the nuclei and nucleoli, binds to XRCC1 and PARP-1, and protects HeLa cells from single-strand DNA breaks. Cell Stress Chaperones 2009, 14(4):391-406.

doi:10.1186/1479-5876-10-96

Cite this article as: Cai et al:: Expression of heat shock protein 70 in nasopharyngeal carcinomas: different expression patterns correlate with distinct clinical prognosis. Journal of Translational Medicine 2012 10:96.

\section{Submit your next manuscript to BioMed Central and take full advantage of:}

- Convenient online submission

- Thorough peer review

- No space constraints or color figure charges

- Immediate publication on acceptance

- Inclusion in PubMed, CAS, Scopus and Google Scholar

- Research which is freely available for redistribution 